\title{
Applications of inclusion behaviour models to a major shear zone system: The Nordfjord-Sogn Detachment Zone in western Norway
}

\author{
Fernando O. Marques ${ }^{\mathrm{a}, *}$, Daniel W. Schmid ${ }^{\mathrm{b}}$, Torgeir B. Andersen ${ }^{\mathrm{b}}$ \\ ${ }^{a}$ Faculdade de Ciências, Departamento de Geologia and IDL, Universidade Lisboa, Edificio C6, Piso 2, 1749-016 Lisbon, Portugal \\ ${ }^{\mathrm{b}}$ Physics of Geological Processes, University of Oslo, P.O. Box 1048, Blindern, 0316 Oslo, Norway \\ Received 10 February 2007; received in revised form 3 May 2007; accepted 15 May 2007 \\ Available online 30 June 2007
}

\begin{abstract}
Rigid inclusion models have reached a stage where one should be able to use them to obtain quantitative values from ductile shear zones. We used natural data collected in three sites and combined analogue and theoretical modelling to assess vorticity, strain, nature of rigid inclusion/ matrix interface and confinement in the large-scale, ductile Nordfjord-Sogn Detachment Zone (NSDZ) of the Caledonides of western Norway. Our study shows that: (1) the observed shape preferred orientation (SPO) at higher structural levels of the NSDZ at Site 1, Gjervika, can be explained by simple shear (pure shear/simple shear ratio $S_{r}=0$ ) associated with a slipping inclusion/matrix interface. (2) The observed SPO at deeper structural levels of the NSDZ at Site 2, near Sandane can be produced by simple shear associated with a significant amount of shortening across the shear zone $\left(S_{r} \approx 1\right)$, acting upon rigid inclusions in slipping contact with the enclosing matrix. (3) Observed back rotated boudins deeper in the NSDZ at Site 3, Biskjelneset, can form in confined flow associated with a considerable amount of shortening across the shear zone $\left(S_{r} \geq 0.4\right)$. (4) The observed tails of porphyroclasts indicate a minimum (at least local) strain of ca. $\gamma \approx 20$. (5) The clasts in the studied shear zones strongly depart from Jeffery's model [Jeffery, G. B., 1922. The motion of ellipsoidal particles immersed in a viscous fluid. Proceedings of the Royal Society of London A102, 161-179].

The large scale extensional NSDZ under investigation shows evidence of strain partitioning: rocks vary from protomylonites to ultramylonites, and the simple shear and pure shear components are heterogeneously distributed. Therefore, we conclude that flow in the NSDZ was very heterogeneous both at the kilometre and the metre scale. However, the present study suggests that the amount of shortening across the shear plane throughout the NSDZ increases with depth, and the flattening component contributes to exhumation of the eclogite facies rocks in its footwall.
\end{abstract} (C) 2007 Elsevier Ltd. All rights reserved.

Keywords: Inclusion orientation and shape; Vorticity; Slipping inclusion/matrix interface; Confinement; Shape preferred orientation (SPO); Ductile shear zone

\section{Introduction}

Studies of ductile shear zones are crucial to understand the tectonic evolution at depth and the exhumation of deep-seated rocks to shallow levels in the lithosphere. Much effort has therefore been put into experimental and theoretical modelling of rock behaviour, in particular the behaviour of effectively rigid inclusions embedded in mylonites (see discussion below). One of the main goals of this research is to comprehend the

\footnotetext{
* Corresponding author. Tel.: +35121750 0000; fax: +351217500064.

E-mail address: fomarques@fc.ul.pt (F.O. Marques).
}

behaviour of such inclusions in a variety of far-field load settings and to identify transient or, ideally, stable shape preferred orientations (SPO) and to relate these results to field studies where SPOs are often observed. Natural SPOs, together with other field data, potentially yield measures for quantities of key interest such as far-field vorticity and total strain. The reason for the particular importance of SPO is that only systematic trends in the data may be interpreted to give meaningful interpretations; in cases where no strong SPO is developed this is not possible. The main problem with the interpretation of SPOs was, until recently, that they generally show inclusion stabilization at shallow positive angles (cf. Fig. 1), which could not be explained by theories that assume an isolated, 


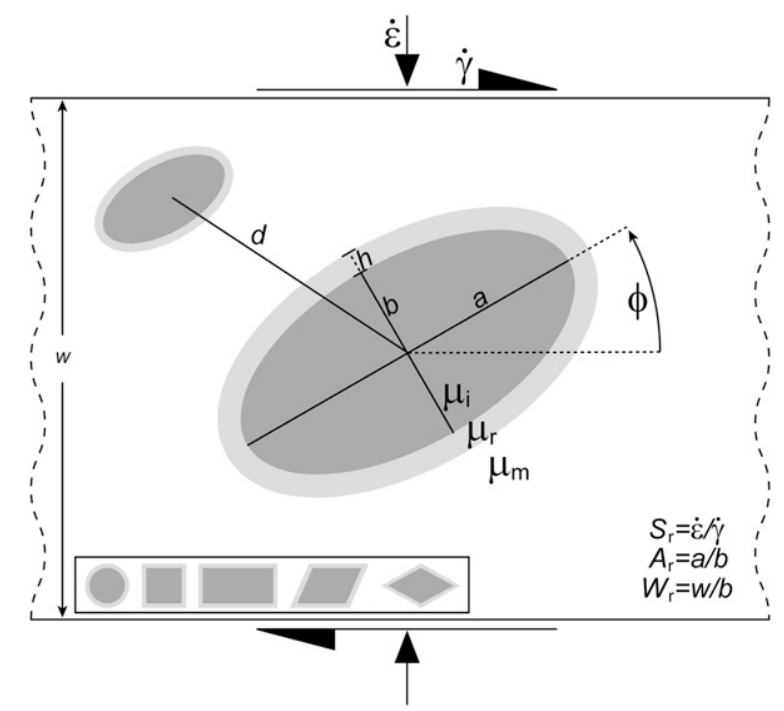

Fig. 1. Sketch of an inclusion in a shear zone. The factors that determine inclusion behaviour are: inclination $\varphi$ (positive counter clockwise), aspect ratio $A_{r}$, ratio $W_{r}$ between shear zone width $(w)$ and inclusion short axis $(b)$, distance to other inclusions $(d)$, presence of a rim with thickness $h$ that controls the degree of welding between inclusion and matrix, shape of the inclusion, viscosities of inclusion $\left(\mu_{i}\right), \operatorname{rim}\left(\mu_{r}\right)$ and matrix $\left(\mu_{m}\right)$, and finally the relative strength of pure to simple shear $S_{r}$. Note that the angle and quadrant convention used (see text) is related to the shear direction, i.e., in top to the left shear zones the above sketch has to be flipped horizontally.

ellipsoidal, rigid inclusion that is perfectly bonded to the matrix (cf. Mancktelow et al., 2002). This mismatch between field data and models has been overcome in recent years by a number of studies that demonstrate the possibility of inclusion stabilization at shallow positive angles; mostly by relaxing the assumptions of isolation and perfect bonding. Given that most of these works focus on model development, it is the aim of this paper to investigate their applicability to field data with the example of a large-scale shear zone: the Nordfjord-Sogn Detachment Zone (NSDZ) in western Norway (Andersen and Jamtveit, 1990; Norton, 1987). In the following we first give a concise overview of the key factors that influence inclusion behaviour in shear zones before we proceed with the application to the NSDZ.

\section{Overview of inclusion models}

\subsection{Fundamental solutions: Aspect ratio, inclination, and material property contrast}

The problem of an inclusion immersed in a matrix of different property is the fundamental building block of heterogeneous materials, occurring in almost all sciences, from biology to physics, medicine and geology. In order to obtain tractable, analytical solutions the shape of the inclusion is often simplified to an ellipsoid. If the interest is focused on slow deformation processes, such as here, two key analytical solutions lay the base for almost all other research: (1) Jeffery's model for rigid ellipsoids in a deforming viscous matrix (Jeffery, 1922), and (2) Eshelby's model for a deformable elastic ellipsoid in a far-field loaded matrix with different properties (Eshelby, 1957, 1959). Note that due to the correspondence principle these solutions can be mapped between viscous and elastic rheologies. Earlier solutions such as for example the one by Muskhelishvili (1953) anticipate some of the results by Eshelby but are restricted to two dimensions, while Jeffery's and Eshelby's are complete three-dimensional solutions. Common to these solutions is the identification of the material property contrast between inclusion and matrix, e.g., $\mu_{i} / \mu_{m}$, the aspect ratio, $A_{r}$, and the inclination $\phi$ as the governing parameters that influence the inclusion behaviour. $A_{r}$ and $\phi$ are two-dimensional simplifications according to Fig. 1.

In the case of structural geology and tectonics, we are particularly interested in rocks affected by deformation in ductile, large-strain shear zones. These are commonly composed of a fine-grained matrix with embedded clasts as a result of shear flow and dynamic recrystallization. The modelling of such ductile shear zones used to assume that the matrix acts as a viscous fluid and the clasts as isolated perfectly bonded rigid inclusions, therefore allowing for application of Jeffrey's solution. However, for simple shear dominated systems Jeffery's model predicts pulsating, synthetic clast rotation. This contradicts frequent field observations of rigid inclusions that show stable fabrics and no signs of rotation (e.g. ten Grotenhuis et al., 2003). Consequently research over the last few decades has been conducted in order to establish factors that can change the rotation behaviour of rigid inclusions. The identified principal factors are: (i) the addition of a pure shear component to simple shear (variable vorticity), (ii) inclusion interaction in multi-inclusion systems, (iii) slip at inclusion/matrix interface, and (iv) flow confinement. These factors may furthermore be affected by the actual shape of the inclusion.

\subsection{Far-field vorticity}

It has long been recognized that vorticity of ductile shear zones deviates, to different degrees, from simple shear, although the latter is believed to be the main component of most shear zones. In particular, a pure shear component, at different angles to the simple shear plane, has been shown to exist in many ductile shear zones (e.g. Sanderson and Marchini, 1984). While the above mentioned fundamental solutions are valid for any kind of far field flow they are somewhat difficult to evaluate (e.g. Freeman, 1987; Ježek et al., 1996). Ghosh and Ramberg (1976) reduced the complexity by studying two-dimensional systems of rigid, isolated elliptical clasts embedded in a viscous matrix that undergoes combined pure and simple shear far-field flow. They established that in such general flows rigid inclusions can rotate syn- and antithetically with respect to the applied simple shear depending on the aspect ratio and the ratio between pure and simple shear, $S_{r}$ (Fig. 1). Consequently, stable inclusion orientations exist at the transition from syn- to antithetic rotation (zero rotation). For transpression, the stable angle lies in the lower right quadrant $\left(-90^{\circ}<\varphi \leq 0^{\circ}\right)$, and for transtension in the upper right quadrant $\left(0^{\circ} \leq \varphi<90^{\circ}\right)$. However, these stable inclinations as a function of the aspect ratio do not reproduce the trends 
observed in nature (e.g. Schmid and Podladchikov, 2004). Further studies on the effects of adding pure shear to simple shear on rotation rate and fabric development include Passchier (1987), Ježek et al. (1996) and Marques and Coelho (2003).

\subsection{Inclusion interaction}

The mylonites in ductile shear zones usually contain embedded porphyroclasts of variable sizes, in a proportion that depends mostly on original rock composition and amount of deformation. Therefore, two contrasting situations can occur: one in which the clasts are relatively isolated and they do not interact (dilute limit, e.g. Jeffery, 1922), and another where the number of clasts is relatively high and inclusions interact. Inclusion interaction in multi-inclusion systems usually leads to tilling effects, which strongly affect inclusion rotation and can bring the inclusion to a stable equilibrium orientation (Arbaret et al., 1996; Fernandez et al., 1983; Ildefonse et al., 1992a,b; Ježek et al., 1994; Mandal et al., 2005; March, 1932; Tikoff and Teyssier, 1994). However, this stabilization mechanism is obviously not viable in cases of SPO defined by relatively isolated clasts.

\subsection{Interface condition}

Many rocks in ductile shear zones (especially those associated with exhumation) show clear signs of significant fluid influx manifested by hydration of dry minerals into hydrated minerals. These fluids percolate mostly along mineral boundaries. Furthermore, it is also common that the new minerals form a weaker phase (mantle) around stronger minerals. Therefore, the contact between inclusion and surrounding matrix may in many cases be slipping to various degrees. Several studies (e.g. Arbaret et al., 2001; Ceriani et al., 2003; Ildefonse and Mancktelow, 1993; Mancktelow et al., 2002; Marques and Cobbold, 1995; Marques and Bose, 2004; Marques and Coelho, 2001; Marques et al., 2005a; Odonne, 1994; Pennacchioni et al., 2001; Schmid and Podladchikov, 2004) have shown that a slipping inclusion/matrix interface greatly influences the rotational behaviour of rigid inclusions: fields of back rotation exist (antithetically to the applied simple shear) and consequently stable inclinations, which are found in the upper right quadrant at angles that are similar to observed natural data.

If the slipping contact is due to the existence of weak mantle phase then the inclination of the clast will be controlled by the viscosity contrast between mantle and matrix and the rate at which the mantle material is produced. Schmid and Podladchikov (2005) analysed this system in detail and derived the "attractor map method" which allows for estimation of the mantle material production rate and bulk strain, simply by measuring the mantle thickness, clast inclination, and total amount of mantle material.

\subsection{Flow confinement}

Strain localization is commonly observed in mylonites in the form of variable thickness shear bands. In layered mylonites, layers of different viscosity deform at different rates, with the generation of microscopic/mesoscopic shear zones in which the ratio $\left(W_{r}\right)$ between their thickness $(W)$ and rigid inclusion's least axis $(b)$ can approach $1\left(W_{r}=w / b\right.$, see Fig. 1, see also figure 5 of Marques et al., 2005c). Marques and Cobbold (1995), Biermeier et al. (2001), Marques and Coelho (2001), Taborda et al. (2004) and Marques et al. (2005b), Marques et al. (2005c) demonstrated experimentally and numerically that confinement can affect matrix flow and the rotation behaviour of rigid inclusions. Depending on the $W_{r}$ value elliptical inclusions can rotate backwards from $\varphi=0^{\circ}$ (opposite to Jeffery's model) and stabilize at shallow positive angles $\left(0^{\circ} \leq \varphi<90^{\circ}\right)$ (Marques and Coelho, 2001).

\subsection{Inclusion shape}

Ghosh and Ramberg (1976) and Arbaret et al. (2001) concluded that the behaviour of rigid inclusions of different shapes perfectly bonded and embedded in a Newtonian matrix undergoing simple shear is not significantly different from that predicted for an enveloping ellipse by Jeffery's analytical solution. However, if the contact is slipping there are substantial differences between different shapes as shown by Mancktelow et al. (2002), Ceriani et al. (2003), Marques and Bose (2004), and Marques et al. (2005a), Marques et al. (2005c). Furthermore, Marques and Bose (2004) and Marques et al. (2005a) showed that, under a permanent slip condition, inclusion shape makes a significant difference regarding the rotation rate: the angle for which the rotation rate becomes zero differs markedly with inclusion shape.

\subsection{Field data collection}

The above sections summarize the cases where permanent SPOs are possible with stabilization in the upper right quadrant, corresponding to the most frequent natural stable inclination: (i) combinations of pure and simple shear with the pure shear extension perpendicular to the shear plane, (ii) inclusion interaction in multi-inclusion systems, (iii) slipping inclusion/ matrix interface, and (iv) flow confinement. SPOs in natural shear zones may be due to any, or even combinations, of these stabilization mechanisms. Application to field data requires the following actions. (i) Identification of clear shear sense indicators. (ii) Identification of stable preferred orientations of rigid inclusions. (iii) Determination of the inclusions' principal axes in order to determine aspect ratio $\left(A_{r}=a / b\right)$, and angle $(\varphi)$ between $a$ and the shear plane (usually assumed to be the mylonitic foliation). (iv) Identification of slip at the inclusion/matrix interface, e.g. presence of fluids and/or weaker phases. (v) Identification of shear flow confinement, e.g. rheologically contrasting layering; by measuring shear zone width and inclusion's least axis to find $W_{r}$.

\section{Application}

In order to illustrate the usefulness of the concepts outlined in the overview section above, we apply them to selected sites at different structural levels within the mylonites of the NSDZ 
in western Norway (Fig. 2). The NSDZ constitutes a system of large-scale ductile extensional shear zones with cumulative top to the west displacements in the order of $50-100 \mathrm{~km}$ (Hacker et al., 2003; Johnston et al., in press; Wain et al., 2000). The NSDZ brings lower pressure Caledonian nappes and overlying sediments of Devonian supra-detachment basins in the hanging wall on top of late Caledonian high- (HP) and ultra-high-pressure (UHP) rocks of the Western Gneiss Complex (WGC) in the footwall (Osmundsen and Andersen, 2001). The footwall is mainly characterized by Middle Proterozoic continental ortho- and paragneisses (see review in Austrheim et al., 2003), which experienced burial to HP and UHP metamorphic conditions during terminal stages of the Caledonian continental collision in the latest Silurian to Lower Devonian (Andersen, 1998; Root et al., 2004). The structurally deepest level rocks exposed in the Caledonides occur in the footwall of the NSDZ and comprise coesite and non-coesite bearing as well as diamond-bearing felsic gneisses and peridotites (e.g. Vrijmoed et al., 2006; Wain et al., 2000). The (U)HP rocks of the WGC underwent rapid decompression and structural exhumation starting at ca $\sim 410 \mathrm{Ma}$ and continuing throughout the Devonian.

The mylonites along the NSDZ were formed by regional extension with top-to-the-west sense of shear and form an up to $5 \mathrm{~km}$ thick zone developed in rocks from both the WGC and the Caledonian nappes (see recent review in Johnston et al., in press). Some segments of the NSDZ mylonites are capped or truncated by brittle normal- to oblique-slip faults representing Permian and Mesozoic reactivation, along which the extensional mylonites are partly excised (Torsvik et al., 1992).

In order to quantify deformation in the NSDZ by fabric analyses, we selected 3 locations within the mylonites (cf. Fig. 2): Site 1 at Gjervika on Atløy within low-grade, greenschist facies phyllonitic rocks near the top of the NSDZ (Swensson and Andersen 1991); Site 2 taken to represent typical mylonitic augen gneisses in the detachment zone which reactivated the original thrust surface separating the nappes and the WGC at Sandane in Nordfjord; and Site 3 at Biskjelneset in a mylonite

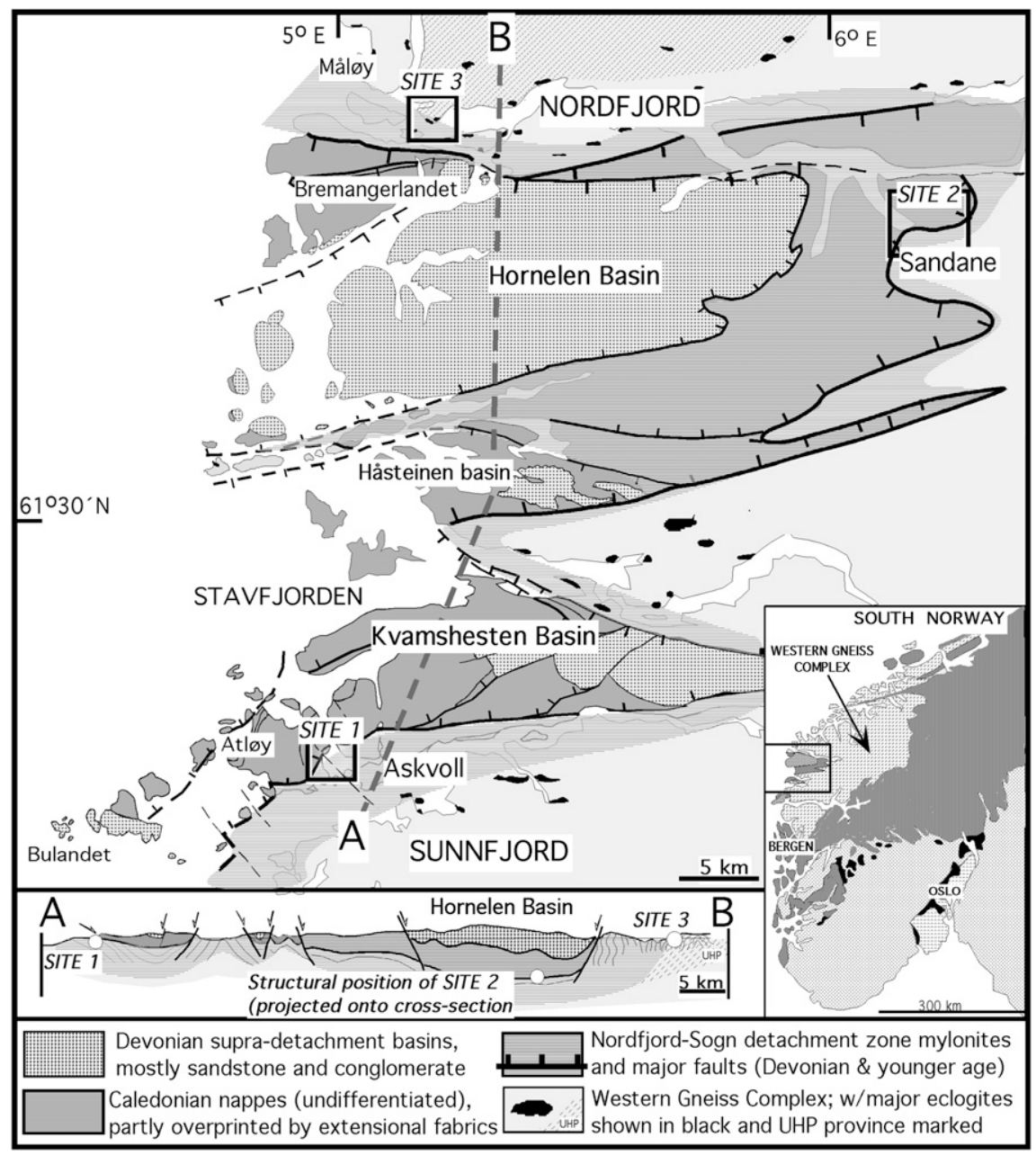

Fig. 2. Map overview of the Nordfjord-Sogn Detachment Zone (NSDZ) in western Norway. NSDZ fabrics are superimposed on Caledonian contractional fabrics in the nappes around the Hornelen basin, whereas the nappes in Sunnfjord are less affected by extension (Andersen et al., 1998). The locations of the studied sites are shown: Site 1, Gjervika; Site 2, Sandane; and Site 3, Biskjelneset. Site 1 is structurally positioned near the top of the NSDZ, where the mylonites are hydrated, strongly affected by retrograde metamorphism and truncated by later faulting. Site 2 is in Augen gneisses developed from megacrystic Precambrian granulites near the contact between the Caledonian nappes and the WGC. Site 3 on the north-shore of Nordfjord is from the deepest levels of the NSDZ where shear fabrics truncate coesite-bearing eclogites. 
zone within the WGC near the coesite-bearing eclogite at Verpeneset in Nordfjord. Site 3 is situated within the HP/ UHP transition zone as defined by Wain et al. (2000).

\section{Site 1, Gjervik, Atløy}

The mylonites near Site 1 (Figs. 2 and 3) were first mapped and described in detail in an unpublished thesis (Hveding, 1992), who based on S-C relationships and micro-scale displacement measurements estimated minimum shear strains $(\gamma)$ to be $\geq 20$ from this area. The site is located near the top of the NSDZ and is characterized structurally by abundant asymmetrical structures and shear bands and mineralogically by retrograde, greenschist facies assemblage (cf. figures $7 \mathrm{~b}$ and 8a in Swensson and Andersen, 1991) of quartz + albite + epidote + biotite + chlorite \pm actinolite \pm calcite \pm sphene (Fig. 3). These retrograde fabrics are superimposed on earlier structures recording decompression from eclogite facies at approximately $2.2-2.5 \mathrm{GPa}$ and $650-700{ }^{\circ} \mathrm{C}$, through $\mathrm{HP}$ amphibolite facies at $1.2-1.4 \mathrm{GPa}$ and $675-700{ }^{\circ} \mathrm{C}$, to greenschist facies conditions at ca. $0.5 \mathrm{GPa}$ and $425-450{ }^{\circ} \mathrm{C}$ (Engvik and Andersen, 2000).

The asymmetrical inclusions embedded in the phyllonitic matrix were analysed by finding the dip and length of the longest fitting axis of the inclusion and orthogonal to it the short axis. The plot of the resulting aspect ratios $\left(A_{r}\right)$ versus inclination $(\varphi)$ is shown in the graph of Fig. 4. The measurements show a clear trend that can be well fitted by a power-law curve. The data is compared to experimental data for a slipping elliptical ice inclusion in PDMS, the equivalent void model, and combined pure and simple shear (transtension).

\section{Site 2, Sandane, Nordfjord}

Site 2 is situated near Sandane in Nordfjord (Fig. 5), where an impressive cross-section of NSDZ mylonites developed from the WGC and Caledonian nappes is well exposed (Young et al., 2007). The rocks selected for detailed analysis are megacrystic K-feldspar augen gneisses formed from Mid-Proterozoic granitoids to monzonites associated with anorthosite, all with a mylonite overprint. The syn-tectonic mineral assemblages of the mylonites are amphibolite- to greenschist facies, locally with feldspar porphyroclasts up to $\mathrm{ca} 10 \mathrm{~cm}$ in size, which are embedded in a matrix dominated by quartz + plagioclase/albite + muscovite + biotite + epidote \pm ilmenite \pm sphene \pm chlorite. The mylonites show increasing hydration and mica-growth with time as indicated by coronas of micas around K-feldspar porphyroclasts in Fig. 5. Eclogite facies rocks are rare near Site 2, but locally preserved as asymmetrical boudins embedded in the mylonites. P-T estimates of the eclogites near Sandane and at equivalent structural levels in Nordfjord yield temperatures of $610-650{ }^{\circ} \mathrm{C}$ and pressures of 2.3-2.5 GPa (Young et al., 2007).

The photograph in Fig. 5 is representative of the Site 2 augen gneiss and shows the following points: (i) $\mathrm{A} \sigma$-porphyroclast (marked 1), with straight tails rooting with asymmetric development at the crests, hence showing very high stair stepping and
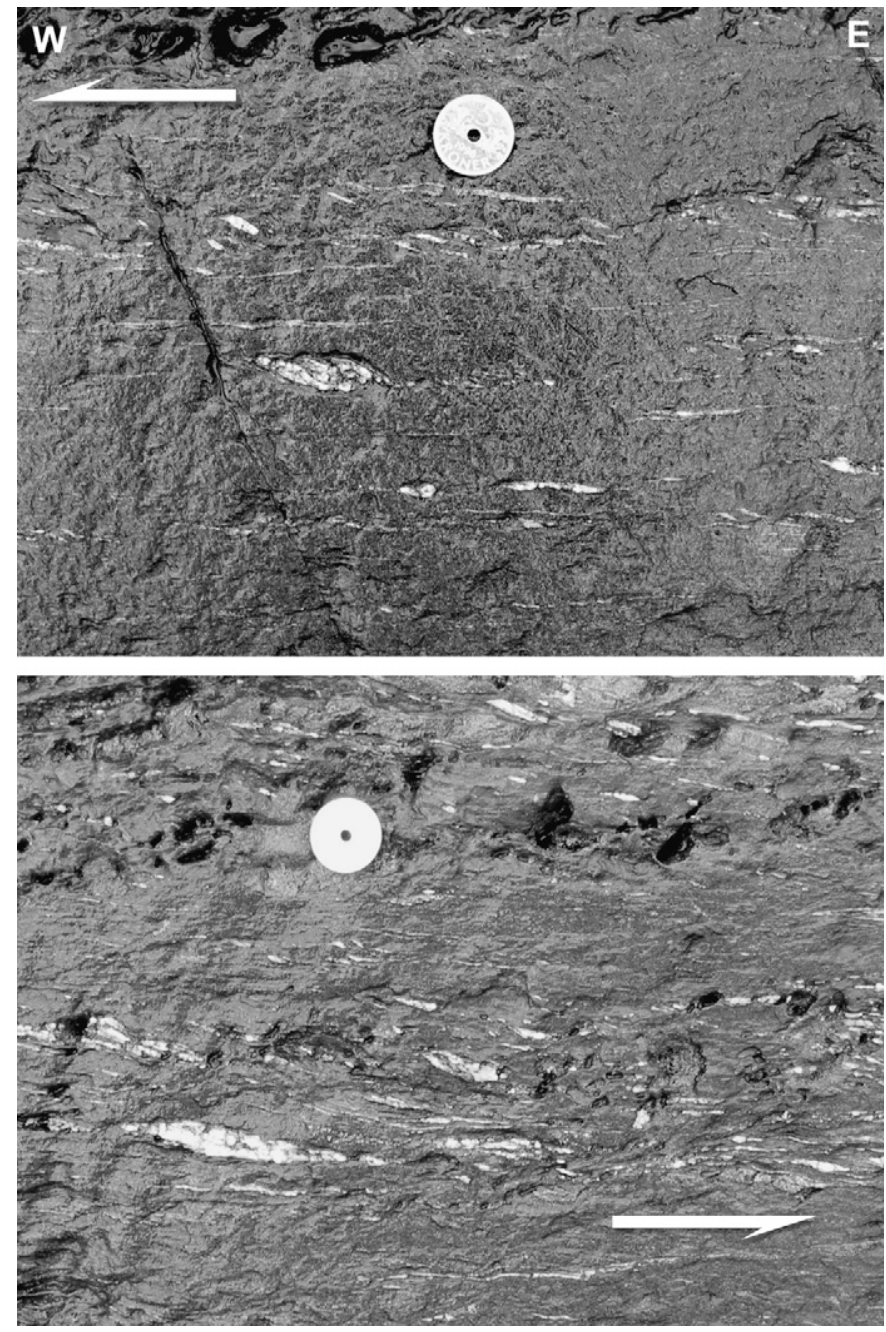

Fig. 3. Phyllonitic mylonites at Site 1, Gjervika on Atløy, near the top of $3 \mathrm{~km}$ thick mylonites developed from the WGC. The asymmetrical inclusions comprise mainly disrupted and strongly attenuated quartz-rich material, which mostly derives from older quartz veins and segregations within the phyllonitic gneiss

clear top to left sense of shear (Marques and Bose, 2004; Bose and Marques, 2004). A dark thin layer of biotite developed around this clast at opposing faces (contraction quadrants, marked by small black arrows), while a white thin rim of quartz (marked by small white arrows) formed at the two other faces (expansion quadrants). (ii) Porphyroclasts with shapes that vary from elliptical (most common, marked 3 to 7), to lozenge (marked 2) or skewed rectangle (marked 8). (iii) Porphyroclasts at negative inclinations (marked 1 and 9) or, more commonly, positive inclinations, cf. Fig. 6. (iv) Lack of well-developed recrystallization tails in most porphyroclasts. (v) Pressure shadow tails as marked by white bigger arrow on the left of porphyroclast 10.

The analysis of the geometrical features of the clasts found at Site 2 is plotted in Fig. 6. The data shows two distinct distributions: (1) a set of positive inclinations and (2) a set of negative inclinations. In both cases larger aspect ratio clasts plot closer to the shear plane than smaller ones. Opposed to the 


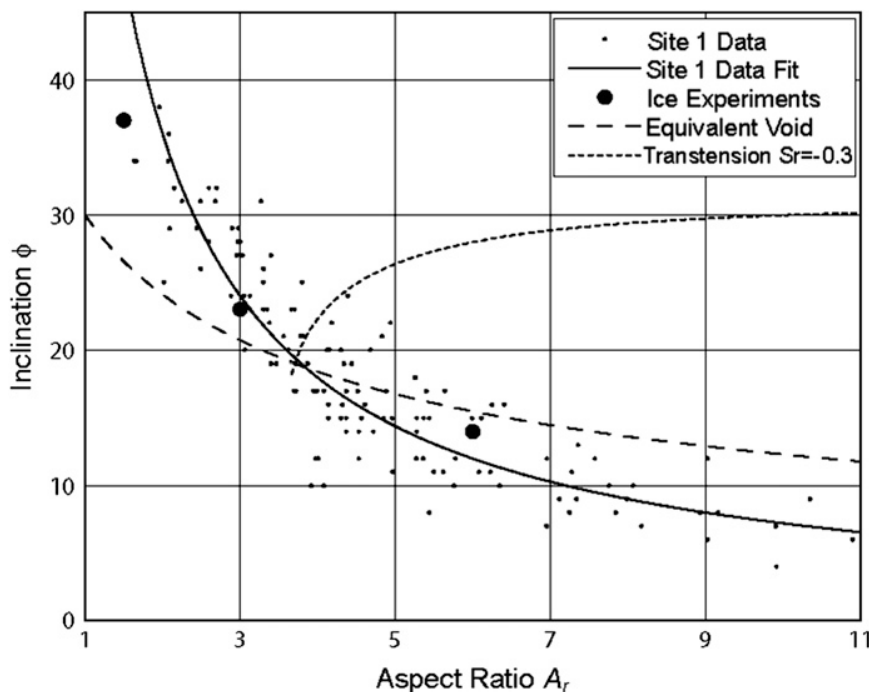

Fig. 4. Aspect ratio vs. inclination from Gjervika, Site 1. The field data is fitted with a power-law and compared to the ice experiments of Marques and Bose (2004), the equivalent void derived by Schmid and Podladchikov (2004), and the transtension $\left(S_{r}=-0.3\right)$ case of combined pure and simple shear (Ghosh and Ramberg, 1976; Marques and Coelho, 2003).

previously discussed Site 1 , the clasts from Site 2 cannot be explained by the model of the slipping interface clast in simple shear (compare "Site 2 data" with "Site 1 data" fit in Fig. 6). However, the trend of clasts with negative inclinations fit well to the perfectly bonded rigid elliptical clasts in combined pure and simple shear with $S_{r}=1$ as derived by Ghosh and Ramberg (1976). Since no published data or theory exists for slipping inclusions in combinations of pure and simple shear, corresponding models had to be run specifically in a fashion similar to Taborda et al. (2004), Schmid and Podladchikov (2005) and Marques et al. (2005a). Using the $S_{r}=1$ value, the shown numerical data (diamonds) was obtained for rigid elliptical clasts with a lubricant layer of $1 \%$ of the clast thickness and a viscosity that is 10,000 times less than the matrix. These numerical data show that the combination of simple shear with a shear zone flattening pure shear stabilizes lubricated clasts at angles substantially, if not too far in this case, below the equivalent simple shear only system. In addition the natural trend of larger aspect ratios plotting closer to the shear plane is reproduced.

The representative shear strain for this outcrop must be larger than 20. This can be obtained by dividing the cumulative length of the tails of $\sigma$-porphyroclast (marked 1 ) by the clast height. Alternatively the attractor map method described by Schmid and Podladchikov (2005), which yields even higher values.

\section{Site 3, Biskjelneset, Nordfjord}

The shear zone at Biskjelneset is located near the UHP eclogite at Verpeneset in Nordfjord (Fig. 7) and represents the deepest structural level affected by the NSDZ mylonitization discussed here. The deformation is strongly heterogeneous with alternating zones of intense deformation in shear

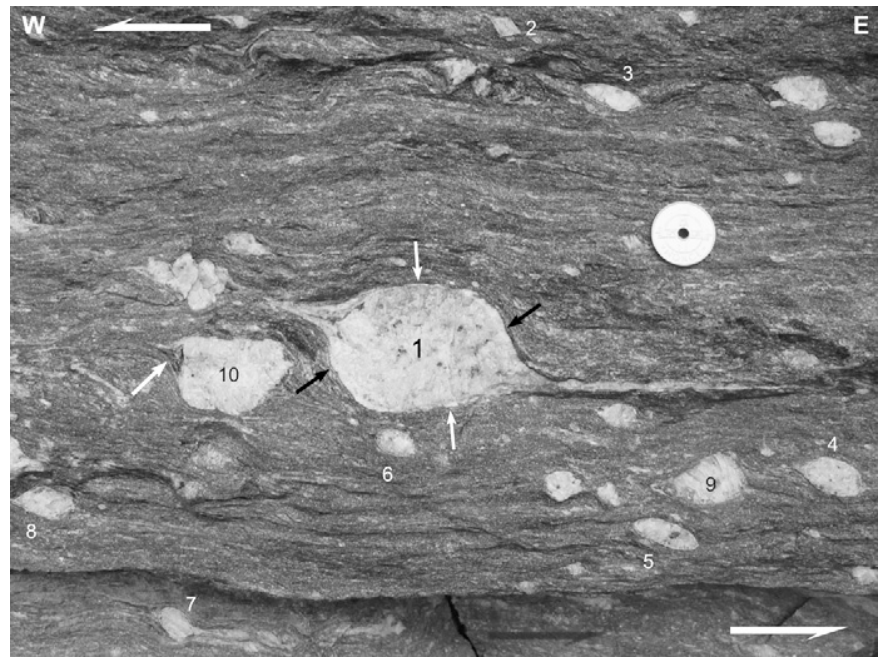

Fig. 5. Photograph from Site 2 near Sandane showing typical augen gneiss developed from megacrystic Precambrian granulite facies gneiss, which commonly occurs in the Caledonian nappes as well as within the WGC.

zones/bands and layers and lenses of variably preserved earlier rocks and mineral assemblages as shown by the numerous lenses of eclogite and locally Pre-Caledonian metamorphic/ igneous rocks in the area (e.g. Krabbendam et al., 2000; Torsvik et al., 1997). The intense shear fabrics have amphibolite facies mineral assemblages, which post-date both eclogites (temperature 650 to $700{ }^{\circ} \mathrm{C}$; pressure 2.7 to $2.9 \mathrm{GPa}$ ) and later high-pressure (1.2 GPa) amphibolites, locally associated with decompression melting (Labrousse et al., 2004).

Observations from the outcrop are represented in Fig. 7 and show that: (i) early deformation produced an intense foliation/ compositional layering and isoclinal folding; (ii) a later stage produced a shear zone (light grey in the middle of the photo) in which the embedded mafic (darker) layer broke up into anti-clockwise rotated boudins; (iii) this later stage also produced tension gashes (at ca. $56^{\circ}$ to the shear zone) in the mafic rock hosting the shear zone. Local detachment folds close to the shear zone boundary attest to the dextral sense of shear. A few tens of metres further to the right (east) in the shear zone there are meter scale rigid inclusions (eclogite lenses) also indicating dextral sense of shear. These observations show that the boudins rotated backwards. Late regional folding around east-west axes controls the present sub-vertical orientation of the foliation in the area (Krabbendam and Wain, 1997).

When trying to determine the vorticity of the shear zone from the back-rotated boudins one should consider the effects of flow confinement and investigate the relative proportions of pure shear and simple shear. Specific numerical models have been run to determine this (see below).

The boudins in the outcrop represented in Fig. 7 can be taken as skewed rectangles. We reproduced the natural shapes in the numerical models, with an $A_{r}$ similar to that measured in outcrop. The measured confinement is about $W_{r}=3$, which corresponds to the ratio of the shear zone width to the thickness of the boudinaged layer. We used numerical simulations following Marques et al. (2005c) to analyse the boudin 


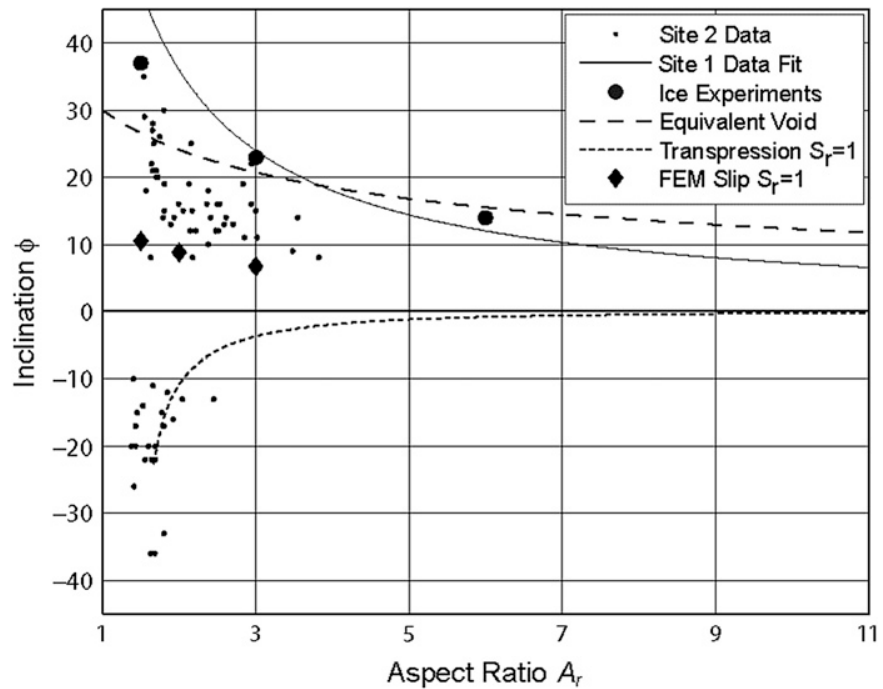

Fig. 6. Aspect ratio vs. inclination from the mylonites of Site 2 at Sandane. The "Site 1 Data Fit", "Ice experiments", and "Equivalent void" are as described in Fig. 4. Transpression is plotted for $S_{r}=1$ according to Ghosh and Ramberg's model (1976). "FEM Slip $S_{r}=1$ " represents finite element calculations for slipping inclusions in pure and simple shear.

behaviour under simple shear associated with a shortening component across the shear zone walls. Note that in order to accomplish (almost) rigid back-rotation of the boudins, there must be extension along the shear direction, which can be achieved by addition of pure shear across the shear plane. Otherwise tilling would impede rotation.

\subsection{Boudin marked 1 in Fig. 7}

The orientation of the natural boudin is presently $\varphi \approx 10^{\circ}$; in order to back rotate this boudin at the initial stage, modelling shows that there should be a pure shear component associated with simple shear, in a proportion $S_{r} \geq 0.15$ even under confinement.

\subsection{Boudin marked 2 in Fig. 7}

The orientation of the natural boudin is presently $\varphi \approx 28^{\circ}$; in order to initiate back rotation of this boudin at the initial stage, even under confinement, modelling shows that there should be a pure shear component associated with simple shear, in a proportion $S_{r} \geq 0.2$. However, to stabilize the boudin at $\varphi \approx 28^{\circ}$, an $S_{r} \geq 0.35$ is needed. Note that the boudin has its longest diagonal parallel to shear zone walls.

\section{Discussion}

We consider the observed fabrics to represent a stable shape preferred orientation because simple or general shear cannot produce transient SPO with the trends and angles shown in the above graphs (cf. Ghosh and Ramberg, 1976; Marques and Coelho, 2003). Three mechanisms are known from theoretical and experimental modelling that can stabilize a rigid, isolated inclusion at shallow positive angles, and, therefore,

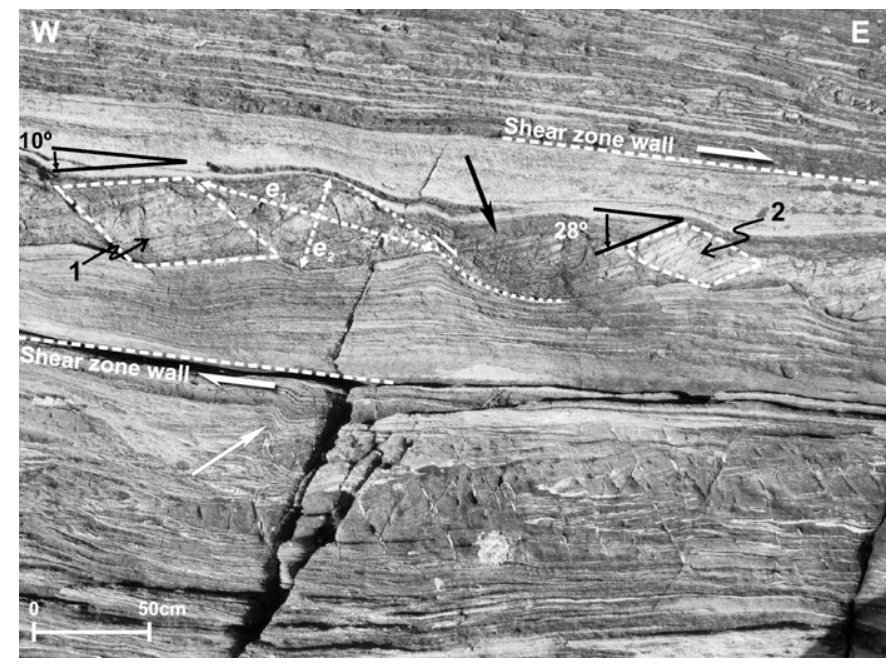

Fig. 7. Asymmetrical, back-rotated boudins from mafic layer (marked by black arrow) in a shear zone at a deep structural level within the NSDZ, at Biskjelneset, Nordfjord. The picture is taken normal to the sub-vertical foliation and parallel to the ENE-WSW stretching lineation. The banded gneiss at this site contains numerous bodies of eclogite with asymmetrical tails that indicate right-lateral sense of shear (white half arrows). Detachment folding marked by white arrow also attests to the deduced shear sense.

produce SPO: (1) Combinations of simple shear and pure shear $\left(S_{r} \neq 0\right)$, with the extension component of pure shear at $90^{\circ}$ to the simple shear plane ("transtension"); (2) slipping boundary between inclusion and matrix; and (3) confined flow, as defined by Marques and Coelho (2001). A combination of these three mechanisms is also possible. The most likely scenarios for the three investigated sites are discussed below.

\subsection{Site 1, Gjervika}

Given the $\varphi-A_{r}$ data from Site 1 (Fig. 4) and the fact that the clasts are found in relative isolation (Fig. 3), the only viable explanation for the observed SPO is that the clast-matrix interface was slipping. This can be seen from the ice in PDMS experiments that correspond very well to the field data and also from the equivalent void conjecture (Fig. 4). Had the interface been welded, then the Ghosh and Ramberg's (1976) model could be applicable, which also predicts stable SPOs at positive angles for cases where the pure shear component is extensional at $90^{\circ}$ to the shear plane. However, the stabilization trend for any such negative $S_{r}$ case is opposite to the field data as illustrated with $S_{r}=-0.3$ in Fig. 4 . We can therefore rule out perfect bonding and, given the good fit between the natural data and the simple shear only lubrication models, we can also rule out the necessity of an additional pure shear component to explain the data.

\subsection{Site 2, Sandane}

The difference between the data from Site 2 and Site 1 (cf. Fig. 6) indicates that the explanation for the Site 2 data from Sandane must be different from Site 1, where the lubricated clast in simple shear alone represents the appropriate model. 
Site 2 data shows two distinct distributions: (1) a set of positive inclinations and (2) a set of negative inclinations. In both cases, larger aspect ratio clasts plot closer to the shear plane than smaller ones. Ghosh and Ramberg's, 1976 model in transtension is not applicable based on the arguments outlined above. However, the clasts with negative inclinations can be fitted to Ghosh and Ramberg's model with a shear zone flattening component that equals the simple shear component, $S_{r}=1$. Note though that the transpression line ceases to exist below a minimum aspect ratio, i.e. clasts with smaller aspect ratios are not stable under the given pure to simple shear ratio and perfect interface bonding. Having established the possibility for a flattening component, the corresponding effects were investigated for lubricated clasts. As shown in Fig. 6 with the specifically run finite element experiments, the addition of a flattening pure shear component shifts the stable inclinations of lubricated clasts closer to the shear plane. The actual angles are too shallow, yet the trend in the data is reproduced. It is obvious that varying the actual amount of pure to simple shear can vary the actual position of the stable inclination curve. However, both positive and negative angle dataset must be fitted with the same pure to simple shear ratio, and therefore $S_{r} \approx 1$ is a reasonable choice. Natural deviations from the ideal model of isolated elliptical clasts may also contribute to the data distribution shown in Fig. 6 as can be inferred from some clasts in Fig. 5.

Evidence for slipping boundaries around part of the clast population is indicated in Fig. 5. Thin rims of mica and/or quartz and/or fine-grained feldspar commonly surround feldspar porphyroclasts, all typically weaker phases than the porphyroclasts, which also are commonly fractured (see Fig. 5). These weak rims could have worked as effective lubricants that kept the rigid feldspar in slipping contact with the mylonitic matrix. Having excluded the possibility of confined flow, the straight tails with very high stair stepping are also indicative that the inclusion was in slipping contact with the matrix (Marques and Bose, 2004; Bose and Marques, 2004). It is therefore a reasonable conclusion that the clasts from Site 2 at Sandane exhibit slipping and non-slipping interfaces with a far field flow condition where simple shear and a flattening pure shear component are of approximately equal strength. The total shear strain must be more than 20 .

\subsection{Site 3, Biskjelneset}

Modelling suggests that part of the observed boudins could rotate backwards if they were free of interaction with neighbouring boudins. However, this is not the case, and tilling effects could justify the measured dips, which are consistently lower than the numerically simulated stable equilibrium orientations for free rotation (Marques et al., 2005c). The pre-existing metamorphic layering may have induced flow localization between rheologically contrasting layers and, hence, made the flow confined. The most developed and rotated boudin (marked 2 in Fig. 7) should be the closest to a stable orientation, for which an $S_{r} \geq 0.4$ is needed.

\section{Conclusions}

We have shown that systematic use of inclusion models can give quantitative results and insights in regions where other quantitative analysis or measurements cannot easily be applied. The present study shows that the exhumation along the NSDZ was not only a result of large-scale simple shear, but that flattening across the shear plane was also significant in the deepest parts of the detachment zone and can be measured to be $S_{r} \approx 1$. The present study suggests an overall increase of the pure shear component with depth in the NSDZ. This shortening component across the NSDZ mylonites adds to the exhumation of the HP/UHP in the footwall and confirms the interpretation by Andersen and Jamtveit (1990) who stated that there is a substantial flattening component in the lower parts of the NSDZ.

In particular we conclude that:

1. Comparison with theoretical and experimental modelling suggests that the studied mylonites at high structural levels of the NSDZ at Gjervika have undergone simple shear $\left(S_{r}=0\right)$, acting upon rigid inclusions in slipping contact with the enclosing matrix.

2. The observed fabric at intermediate structural levels of the NSDZ at Sandane can be produced by simple shear associated with a significant amount of shortening normal to the shear plane $\left(S_{r} \approx 1\right)$, acting upon rigid inclusions. Part of the inclusion population is perfectly welded while the other is in slipping contact with the enclosing matrix.

3. The observed back rotation of boudins at deep levels of the NSDZ at Biskjelneset can be explained by confined flow associated with a significant component of shortening across the shear plane $\left(S_{r} \geq 0.4\right)$.

\section{Acknowledgements}

This is a contribution to research project TEAMINT (POCTI/CTA/48137/2002) funded by FCT. A centre of excellence grant (SFF) from the Norwegian Research Council to Physics of Geological Processes (PGP) supported this study. Reviews by L. Arbaret and A. Brogi, and editorial work by J. Hippert helped improve the quality of this paper.

\section{References}

Andersen, T.B., 1998. Extensional tectonics in the Caledonides of southern Norway, an overview. Tectonophysics 285 (3-4), 333-351.

Andersen, T.B., Jamtveit, B., 1990. Uplift of deep crust during orogenic extensional collapse-a model based on field studies in the Sogn-Sunnfjord Region of Western Norway. Tectonics 9 (5), 1097-1111.

Andersen, T.B., Berry, H.N., Lux, D.R., Andresen, A., 1998. The tectonic significance of pre-Scandian Ar-40/Ar-39 phengite cooling ages in the Caledonides of western Norway. Journal of the Geological Society 155, 297-309.

Arbaret, L., Diot, H., Bouchez, J.L., 1996. Shape fabrics of particles in low concentration suspensions: 2D analogue experiments and application to tiling in magma. Journal of Structural Geology 18 (7), 941-950. 
Arbaret, L., Mancktelow, N.S., Burg, J.P., 2001. Effect of shape and orientation on rigid particle rotation and matrix deformation in simple shear flow. Journal of Structural Geology 23 (1), 113-125.

Austrheim, H., Corfu, F., Bryhni, I., Andersen, T.B., 2003. The Proterozoic Hustad igneous complex: a low strain enclave with a key to the history of the Western Gneiss Region of Norway. Precambrian Research 120 (1-2), 149-175.

Biermeier, C., Stuwe, K., Barr, T.D., 2001. The rotation rate of cylindrical objects during simple shear. Journal of Structural Geology 23 (5), 765-776.

Bose, S., Marques, F.O., 2004. Controls on the geometry of tails around rigid circular inclusions: insights from analogue modelling in simple shear. Journal of Structural Geology 26, 2145-2156.

Ceriani, S., Mancktelow, N.S., Pennacchioni, G., 2003. Analogue modelling of the influence of shape and particle/matrix interface lubrication on the rotational behaviour of rigid particles in simple shear. Journal of Structural Geology 25 (12), 2005-2021.

Engvik, A.K., Andersen, T.B., 2000. Evolution of Caledonian deformation fabrics under eclogite and amphibolite facies at Vardalsneset, Western Gneiss Region, Norway. Journal of Metamorphic Geology 18 (3), 241-257.

Eshelby, J.D., 1957. The determination of the elastic field of an ellipsoidal inclusion, and related problems. Proceedings of the Royal Society of London Series A- Mathematical and Physical Sciences 241 (1226), 376-396.

Eshelby, J.D., 1959. The elastic field outside an ellipsoidal inclusion. Proceedings of the Royal Society of London Series A. Mathematical and Physical Sciences 252 (1271), 561-569.

Fernandez, A., Feybesse, J.L., Mezure, J.F., 1983. Theoretical and experimental-study of fabrics developed by different shaped markers in two-dimensional simple shear. Bulletin De La Societe Geologique De France 25 (3), 319-326.

Freeman, B., 1987. The behavior of deformable ellipsoidal particles in 3-dimensional slow flows-implications for geological strain analysis. Tectonophysics 132 (4), 297-309.

Ghosh, S.K., Ramberg, H., 1976. Reorientation of incluions by combination of pure shear and simple shear. Tectonophysics 34 (1-2), 1-70.

Hacker, B.R., Andersen, T.B., Root, D.B., Mehl, L., Mattinson, J.M., Wooden, J.L., 2003. Exhumation of high-pressure rocks beneath the Solund Basin, Western Gneiss Region of Norway. Journal of Metamorphic Geology 21 (6), 613-629.

Hveding, B.S., 1992. En strukturgeologisk unders $\varnothing$ kelse av mylonittsonen under Dalsfjordforkastningen i Atløy-Askvoll området, Sunnfjord.1 b. flere pag. 2 kart i lomme, Hovedoppgave i geologi-Universitetet i Oslo.

Ildefonse, B., Launeau, P., Bouchez, J.L., Fernandez, A., 1992a. Effect of Mechanical Interactions on the Development of Shape Preferred Orientations-a 2-Dimensional Experimental Approach. Journal of Structural Geology 14 (1), 73-83.

Ildefonse, B., Sokoutis, D., Mancktelow, N.S., 1992b. Mechanical interactions between rigid particles in a deforming ductile matrix. Analogue experiments in simple shear flow. Journal of Structural Geology 14 (10), 1253-1266.

Ildefonse, B., Mancktelow, N.S., 1993. Deformation around Rigid Particles-the Influence of Slip at the Particle Matrix Interface. Tectonophysics 221 (3-4), 345-359.

Jeffery, G.B., 1922. The motion of ellipsoidal particles immersed in a viscous fluid. Proceedings of the Royal Society of London A102, 161-179.

Ježek, J., Melka, R., Schulmann, K., Venera, Z., 1994. The behavior of rigid triaxial ellipsoidal particles in viscous flows modeling of fabric evolution in a multiparticle system. Tectonophysics 229 (3-4), 165-180.

Ježek, J., Schulmann, K., Segeth, K., 1996. Fabric evolution of rigid inclusions during mixed coaxial and simple shear flows. Tectonophysics 257 (2-4), 203-221.

Johnston, S., Hacker, B., Andersen, T.B., in press. Exhuming Norwegian ultrahigh-pressure rocks: overprinting extensional structures and the role of the Nordfjord-Sogn Detachment Zone. Tectonics.

Krabbendam, M., Wain, A., 1997. Late-Caledonian structures, differential retrogression and structural position of (ultra)high-pressure rocks in the Nordfjord-Stadlandet area, Western Gneiss region. Bulletin-Norges Geologiske Undersøkelse 432, 127-139.
Krabbendam, M., Wain, A., Andersen, T.B., 2000. Pre-Caledonian granulite and gabbro enclaves in the Western Gneiss Region, Norway: indications of incomplete transition at high pressure. Geological Magazine 137 (3), $235-255$.

Labrousse, L., Jolivet, L., Andersen, T.B., Agard, P., Maluski, H., Schärer, U., 2004. Pressure-temperature-time-deformation history of the exhumation of ultra-high-pressure rocks in the Western Gneiss Region, Norway. Geological Society of America, Special paper 380, 155-185.

Mancktelow, N.S., Arbaret, L., Pennacchioni, G., 2002. Experimental observations on the effect of interface slip on rotation and stabilisation of rigid particles in simple shear and a comparison with natural mylonites. Journal of Structural Geology 24 (3), 567-585.

Mandal, N., Samanta, S.K., Bhattacharyya, G., Chakraborty, C., 2005. Rotation behaviour of rigid inclusions in multiple association: insights from experimental and theoretical models. Journal of Structural Geology 27 (4), 679-692.

March, A., 1932. Mathematische Theorie der Regelung nach der Korngestalt bei affiner Deformation. Zeitschrift fur Kristallographie 81, 285-297.

Marques, F.O., Bose, S., 2004. Influence of a permanent low-friction boundary on rotation and flow in rigid inclusion/viscous matrix systems from an analogue perspective. Tectonophysics 382 (3-4), 229-245.

Marques, F.G., Cobbold, P.R., 1995. Development of highly non-cylindrical folds around rigid ellipsoidal inclusions in bulk simple shear regimes: natural examples and experimental modelling. Journal of Structural Geology 17 (4), 589-602.

Marques, F.O., Coelho, S., 2001. Rotation of rigid elliptical cylinders in viscous simple shear flow: analogue experiments. Journal of Structural Geology 23 (4), 609-617.

Marques, F.O., Coelho, S., 2003. 2-D shape preferred orientations of rigid particles in transtensional viscous flow. Journal of Structural Geology 25 (6), 841-854.

Marques, F.O., Taborda, R., Antunes, J., 2005a. Influence of a low-viscosity layer between rigid inclusion and viscous matrix on inclusion rotation and matrix flow: A numerical study. Tectonophysics 407 (1-2), 101-115.

Marques, F.O., Taborda, R., Bose, S., Antunes, J., 2005b. Effects of confinement on matrix flow around a rigid inclusion in viscous simple shear: insights from analogue and numerical modelling. Journal of Structural Geology 27 (3), 379-396.

Marques, F.O., Taborda, R.M., Antunes, J.V., 2005c. 2D rotation of rigid inclusions in confined bulk simple shear flow: a numerical study. Journal of Structural Geology 27 (12), 2171-2180.

Muskhelishvili, N.I., 1953. Some basic problems of the mathematical theory of elasticity. Noordhoff Groningen.

Norton, M.G., 1987. The Nordfjord-Sogn Detachment, W Norway. Norsk Geologisk Tidsskrift 67 (2), 93-106.

Odonne, F., 1994. Kinematic behavior of an interface and competence contras$\mathrm{t}$ - analog models with different degrees of bonding between deformable inclusions and their matrix. Journal of Structural Geology 16 (7), 997-1006.

Osmundsen, P.T., Andersen, T.B., 2001. The middle Devonian basins of western Norway: sedimentary response to large-scale transtensional tectonics? Tectonophysics 332 (1-2), 51-68.

Passchier, C.W., 1987. Stable positions of rigid objects in noncoaxial flow-a study in vorticity analysis. Journal of Structural Geology 9 (5-6), 679-690.

Pennacchioni, G., Di Toro, G., Mancktelow, N.S., 2001. Strain-insensitive preferred orientation of porphyroclasts in Mont Mary mylonites. Journal of Structural Geology 23 (8), 1281-1298.

Root, D.B., Hacker, B.R., Mattinson, J.M., Wooden, J.L., 2004. Zircon geochronology and ca. 400 Ma exhumation of Norwegian ultrahigh-pressure rocks: an ion microprobe and chemical abrasion study. Earth and Planetary Science Letters 228 (3-4), 325-341.

Sanderson, D.J., Marchini, W.R.D., 1984. Transpression. Journal of Structural Geology 6, 449-458.

Schmid, D.W., Podladchikov, Y.Y., 2004. Are isolated stable rigid clasts in shear zones equivalent to voids? Tectonophysics 384 (1-4), 233-242.

Schmid, D.W., Podladchikov, Y.Y., 2005. Mantled porphyroclast gauges. Journal of Structural Geology 27 (3), 571-585.

Swensson, E., Andersen, T.B., 1991. Contact Relationships between the Askvoll Group and the Basement Gneisses of the Western Gneiss Region 
(Wgr), Sunnfjord, Western Norway. Norsk Geologisk Tidsskrift 71 (1), $15-27$.

Taborda, R., Antunes, J., Marques, F.O., 2004. 2-D rotation behavior of a rigid ellipse in confined viscous simple shear: numerical experiments using FEM. Tectonophysics 379 (1-4), 127-137.

ten Grotenhuis, S.M., Trouw, R.A.J., Passchier, C.W., 2003. Evolution of mica fish in mylonitic rocks. Tectonophysics $372(1-2), 1-21$.

Tikoff, B., Teyssier, C., 1994. Strain and fabric analyses based on porphyroclast interaction. Journal of Structural Geology 16 (4), 477-491.

Torsvik, T.H., Andersen, T.B., Eide, E.A., Walderhaug, H.J., 1997. The age and tectonic significance of dolerite dykes in western Norway. Journal of the Geological Society 154, 961-973.

Torsvik, T.H., Sturt, B.A., Swensson, E., Andersen, T.B., Dewey, J.F., 1992. Paleomagnetic dating of fault rocks-evidence for Permian and Mesozoic movements and brittle deformation along the extensional Dalsfjord Fault, Western Norway. Geophysical Journal International 109 (3), $565-580$.

Vrijmoed, J.C., Van Roermund, H.L.M., Davies, G.R., 2006. Evidence for diamond-grade ultra-high pressure metamorphism and fluid interaction in the Svartberget Fe-Ti garnet peridotite-websterite body, Western Gneiss Region, Norway. Mineralogy and Petrology 88 (1-2), 381-405.

Wain, A., Waters, D., Jephcoat, A., Olijynk, H., 2000. The high-pressure to ultrahigh-pressure eclogite transition in the Western Gneiss Region, Norway. European Journal of Mineralogy 12 (3), 667-687.

Young, D.J., Hacker, B.R., Andersen, T.B., Corfu, F., 2007. Prograde amphibolite facies to ultrahigh-pressure transition along Nordfjord, western Norway: Implications for exhumation tectonics. Tectonics 26, TC1007, doi:10.1029/2004TC001781. 